\title{
MODELLING VEHICLE EMISSIONS USING ARTIFICIAL NEURAL NETWORK AND MULTIPLE LINEAR REGRESSION METHODS
}

\author{
Hichem Hassine ${ }^{* 1,2}$, Fatma Omrane ${ }^{2}$, Maher Barkallah ${ }^{1}$, Jamel Louati $^{1}$ and \\ Mohamed Haddar ${ }^{1}$ \\ ${ }^{1}$ Laboratory of Mechanics, Modelling and Production, National Engineering School of Engineering of Sfax, Tunisia \\ ${ }^{2}$ Higher Institute of Transport and Logistics of Sousse, Sousse University, Tunisia
}

Received 25 April 2020; received in revised form 15 April 2021; accepted 20 April 2021

\begin{abstract}
The road transport sector plays a vital role in economic development and vehicle numbers are growing. It provides a set of services to meet the different demands of travel and it is a necessity for human civilization. However, although it is an essential element in regional development schemes, it generates negative externalities, thus constituting one of the most important sources of environmental pollution. This paper aims to develop modelling vehicle emissions, especially, the $\mathrm{HC}, \mathrm{CO}$ and $\mathrm{NOx}$ based on experimental speed profiles, acceleration and technical parameters related to the used vehicle. This helps to determine and study vehicle emissions factor related to different pollutant. Two methods are used to develop two different empirical models: the multiple regression and Artificial Neural Network (ANN). The developed approach was applied to two types of vehicle with different technical characteristics. It was observed that the multiple linear regression method allows to predict vehicle emissions with a coefficient of determination between 0.723 and 0.921 but the ANN model can predict exhaust gases with a correlation coefficient in the range of 0.95-0.99. Simulation results demonstrate the efficiency and superiority of the ANN tool to estimate vehicle emissions compared to multiple linear regression approach.
\end{abstract}

Keywords: Vehicle emissions; Speed profile; Artificial Neural Network; Multiple linear regression; Vehicle specific power (VSP).

(C) 2021 Journal of Urban and Environmental Engineering (JUEE). All rights reserved.

\footnotetext{
*Correspondence to: Hichem Hassine. E-mail: hassinehichem@yahoo.fr
} 


\section{INTRODUCTION}

The accessibility for pedestrians has received increasing consideration during planning in the recent years. The impact of COVID-19 and the measures that are taken has impacted the local and the global transport systems as well. There is a need to achieve minimum physical distance of about two meters between two persons to prevent the spread of COVID-19, as per the recommendations of the world health organization. So, it is imperative to analyze the present scenario of the urban streets in view of achieving the required distance among the pedestrians; and rethinking about the planning process from the lessons learned to safeguard the future generation from the possible situations like COVID-19. It has been established through researches that the development of pedestrian responsive streets contributes towards overall sustainable development by means of economic growth, as well as social and environmental welfare (Elsawy et al., 2019; Southworth, 2005). The pedestrian accessibility has been considered to be responsible for the traffic-calming at the city level, whereas urban design has been said to intend to provide pedestrian friendly design elements at the neighborhood level. Studies suggest, Pedestrian Street is an important component of a sustainable urban system. However, most of the streets have been constructed during motorization periods, so designed considering more for motorized vehicles, and on street pedestrian spaces is typically ignored (Jain and Moraglio, 2014).

The literature suggests that the street network characteristics including degree of connectivity and level of accessibility of a street segment, is among major factors in deciding the pedestrian density at that segment (Ozbil et al., 2011). This methodology to evaluate the accessibility measures of a street network is called as the configurational approach. The configurational approach depending upon the topological attributes of the street network, are assumed to be capable of elucidating the behavioral pattern of the people in an urban system (Ozbil et. al, 2011). Studies suggest that one of the established methods based upon the configurational approach, methodology of space syntax, has been derived from topological and graphical analysis of the street network in the urban system (Hillier et al. 1993; Hillier, 1996). The topological factors, like connectivity, integration and choice, are the deciding factors for evaluating degree of accessibility of a street segment from the user perspective, in the space syntax analysis using axial maps (Hillier et al., 1993; Hillier and Iida, 2005). The number of axial lines directly crossing a line, measures the degree of connectivity of that line under investigation (Liu and Jiang, 2012). The integration level describes the average of topological distances from a definite axial line segment to each of the remaining lines in a network (Jiang, 2008). The space syntax static street network model explains the dynamism of network in a simple but robust way and allows for a quick syntactical analysis (Kim and Penn, 2004). However, while the method can be applied to explain the spatial configurations of an urban system, the exposition of the analyses should be in concomitant with the study of socio-economic processes and behavioral pattern. The topological arrangement has considerable influence on the pedestrian movement. The pedestrian movements can be described either purely by a topological arrangement, or in consideration with other factors, like, land use pattern, road width, and socio-psychological factors (Penn et al., 1998; Jiang, 2002). The effects of land use attractiveness on pedestrian behavior are also ascertained in the recent researches. Study suggests that the land use type such as commercial, offices, recreational parks, and public transport sites has significant impact on the pedestrian density and behavior in their adjacent areas (Ozbil 2011). Several studies attempted to associate both of the land use and configurational factors. Ozer and Kubat (2007) found that pedestrian volume has maximum dependence on the sense of security from misconduct and accidents, while other important influencing factors were, results of the space syntax analysis and land use pattern (Ozer and Kubat, 2007). The correlation and regression analysis can measure interrelation between the spatial layout and the socio-economic indicators, to test sociospatial hypotheses, or to develop simulation models for evaluating socio-economic impact of spatial layout pattern (Kumari and Devadas, 2017). These predictive models may predict indicators, like rate of crime, traffic flow, number of accidents, satisfaction, ease of walk, economy generation, etc. (Klarqvist, 1993).

The major problem in the street network planning is the lack of reliable spatial as well as non-spatial data required for this purpose. The relevant, reliable, updated, easily accessible, and affordable data is rudimentary for an effective research analysis and decision making process. The demand for authentic information requires new strategies in which data regarding street network should be recognized, collected, deposited, recovered, managed, analyzed, transferred, and presented efficiently. In recent researches, Geographical Information System (GIS) has commonly been used for traffic and transportation planning, as it can be an effective tool to storage, process, and analyze the spatial and non-spatial data effectively (Das et al., 2019). GIS has the ability to access and analyze the data in view of the actual spatial location overlaid on a base map of the area under investigation. The main advantage of employing GIS is 
due to its capability of performing tasks, such as thematic mapping, network analysis, charting, operational with a number of layers of data and the overlay analysis, as well as owing to its friendly interface with external programs and software for data management and decision support (Morara and Bertolinib, 2013). There is ample opportunity to utilize tools and techniques like, GIS and space syntax for analyzing the existing pedestrian streets to assess its adaptability to achieve particular pedestrian space.

\section{Methodology}

Modelling vehicle emissions represents one of the main objectives in order toward sustainable development and determines the effect of different parameters on the evolution of the quantity of gas emitted by vehicles and transport sector in general. We develop in this paper a global approach allowing to model vehicle emissions based on experimental data related to speed, acceleration and technical parameters of the used vehicles. The modelling of emitted gas is based on two different methods: the artificial neural networks and the multiple linear regression method. Figure 1 presents the flowchart of the proposed approach. This procedure reposes on four levels:

Step 1: The choice of the studied site and the different used vehicles.

Step 2: Collect data related to: speed, acceleration and ecological emissions.

Step 3: Modelling vehicle emissions (CO, HC and NOx) using multiple linear regression and artificial neural network.

Step 4: Comparing results referring to several indicators.

\section{Study area and vehicles parameters}

Figure 2 shows the urban site considered for the present study. It is an urban segment named (GP1) in the Sousse city (Tunisia). The studied segment is a four-lane road with a median separating traffic flow in opposite directions. It has a length of $4 \mathrm{~km}$ and on either side of the land use is varying from institutional with educational and research institutes such as the national engineering school of Sousse and the center for research in microelectronics and nanotechnology and also, residential buildings. In order to estimate emissions of air pollutants, two vehicles were selected, of which two drivers with a speed profile was quantified second by second for each vehicle. Table 1 presents the characteristics of the two used vehicles "LDV3" and "LDV5".

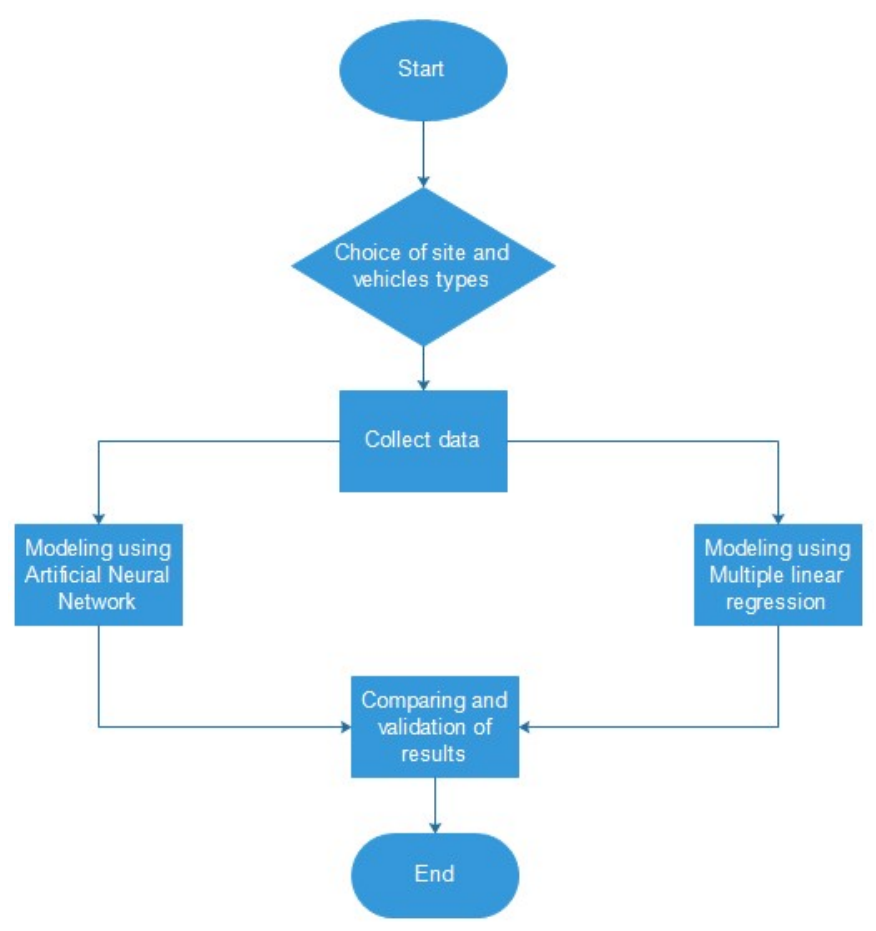

Fig. 1 Flowchart of the proposed approach

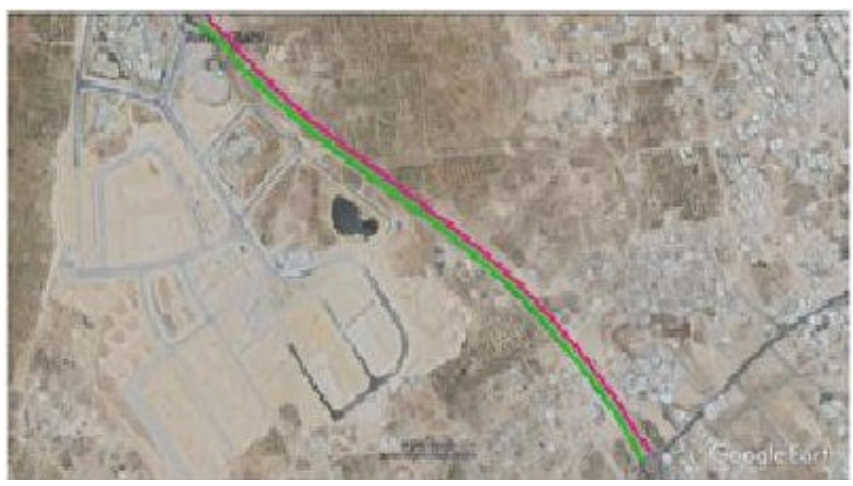

Fig. 2 The studied site

Table 1. Characteristics of the used vehicles

\begin{tabular}{|c|c|c|}
\hline Vehicle setting & LDV 3 & LDV 5 \\
\hline Transmission & Conventional & Conventional \\
\hline Fuel type & Gasoline & Diesel \\
\hline Transmission type & Manual & Manual \\
\hline Name of vehicle & VEH_SMCAR & $\begin{array}{c}\text { VEH_COMP } \\
\text { ACT }\end{array}$ \\
\hline Vehicle mass (kg) & 940 & 1280 \\
\hline CD: coefficient of drag & 0.34 & 0.3 \\
\hline $\begin{array}{l}\text { FA: Front surface of the vehicle } \\
\left(\mathrm{m}^{2}\right)\end{array}$ & 2 & 2.1 \\
\hline Density of the air $\left(\mathrm{kg} / \mathrm{m}^{3}\right)$ & 12.256 & 12.256 \\
\hline Severity $\left(\mathrm{m} / \mathrm{s}^{2}\right)$ & 9.81 & 9.81 \\
\hline Version & 1995 & 2009 \\
\hline $\begin{array}{l}\text { Wheelbase: distance between the } \\
\text { front axle and the rear axle }(\mathrm{m})\end{array}$ & 2.360 & 2.642 \\
\hline Maximum power $(\mathrm{kW})$ & 85 & 96 \\
\hline
\end{tabular}




\section{Collect data and experimental procedure}

The results of present investigation shows that the space available per pedestrian various from $0.7 \mathrm{sqm}$ to 17.0 sqm (Fig. 3a). Most of the main market street has less than $4.0 \mathrm{sqm}$ pedestrian space available, which is much less than required (4 sqm pedestrian spaces to achieve minimum physical distance of $2 \mathrm{~m}$ ) in the situation like COVID-19. The attractiveness has been calculated by measuring the level of various selected indicators of attractiveness for a commercial street, which are: point of interest; adequacy of movement space; quality of goods and services; road condition; light facility; and nearness to parking space (Table 1). During the experimental procedure, we propose to determine the speed profile and acceleration related to each type of vehicle in the studied site. These data were collected during April 2019 under peak and an off-peak hour. Then, in order to estimate emissions of air pollutants $\mathrm{CO}, \mathrm{HC}$ and NOx, a microscopic model of fuel consumption and exhaust emissions namely the ADVISOR model, was used. This model is able to capture instant modal activities of vehicles and defines the relationship between emissions of pollutants in the exhaust phase of the vehicles and their operating modes. The emissions of NOx, $\mathrm{HC}$ and $\mathrm{CO}$ from the exhaust pipe and the corresponding velocity and acceleration variation of the vehicle will be collected on a secondby-second basis. ADVISOR is based on the following model:

$$
\mathrm{F}=\mathrm{m} \times \mathrm{g} \times \mathrm{C}_{\mathrm{rr}}+\frac{1}{2} \times \rho \times \mathrm{C}_{\mathrm{D}} \times \mathrm{A} \times \mathrm{v}^{2}+\mathrm{m} \times \mathrm{a}+\mathrm{m} \times g \times \sin (\theta)
$$

with: F: Force required on vehicle wheels m: mass of the vehicle, a: acceleration $\left(\mathrm{m} / \mathrm{s}^{2}\right)$, g: center of gravity, $\mathrm{C}_{\mathrm{rr}}$ : rolling resistance coefficient between the tires and the road surface, $\rho$ : density of the air $\left(\mathrm{kg} / \mathrm{m}^{3}\right), \mathrm{C}_{\mathrm{D}}$ : drag coefficient, A: front surface of the vehicle $\left(\mathrm{m}^{2}\right), \mathrm{v}$ : Vehicle speed $(\mathrm{m} / \mathrm{s})$, and $\theta$ : angle of inclination. In this section, we propose to present the implementation of Artificial Neural Network method to predict second by second emissions of vehicle. It is suitable for implementation in microscopic analysis. This model is based on an analysis of the impact of input variables on emissions and it will be applied to the measurement of pollutant releases.



Fig. 3 Structure of the neural network

\section{Artificial neural networks method}

ANNs are models based on a mathematical basis inspired by the functioning of the nervous systems (Directive 2002/49; Gardner and Dorling, 1998; Elena et al., 2006; Specht, 1991; Omer et al., 2019), composed of a number of interconnected entities. These networks are widely used to solve various problems in different domains due to their strong non-linear mapping capability, high accuracy for learning as well as robust results. The basic tasks completed by the ANN are: pattern recognition, model classification and prediction. It is based on three sets of rules: multiplication, summation, and activation. Firstly, each value of an input variable (Input i) is multiplied by its own individual weight $\left(\mathrm{W}_{\mathrm{i}}\right)$. Then, the summation function is responsible of gathering all the input variables weighted by their individual weights as well as the bias (b). Finally, the sum of the previously weighted inputs and the bias must go through the activation function of the trough known as the transfer function to obtain the output of this procedure.

\section{ANN method to predict vehicles emissions}

In this study, ANN has been used as a predictive model of vehicle exhaust emissions. Generally, it includes three essential layers: an input layer, one or more hidden layers, and an output layer. ANN starts with random weights for all neurons and the number of hidden layers and neurons in each hidden layer is the parameter to be chosen in the model construction. Accordingly, the model was created on the basis of two most significant inputs including vehicle speed $(\mathrm{m} / \mathrm{s})$ and acceleration $\left(\mathrm{m} / \mathrm{s}^{2}\right)$.

\section{Modeling vehicle emission using Artificial Neural Network (ANN) method}

Since the neural network allows only one output, separate models have been developed for each of the transmit outputs $(\mathrm{CO}, \mathrm{HC}$ et $\mathrm{NOx})$ on $(\mathrm{g} / \mathrm{s})$, thus the selected structure of the ANN as shown in Fig. 3. The Levenberg-Marquardt learning algorithm was used in this study. The weight $(\mathrm{w})$ which examines the propagation value $(x)$ and the output value $(O)$ of each node is modified using the value of the previous layer according to the following equation proposed by Zhao (1999):

$$
\mathrm{O}=\mathrm{f}\left(\mathrm{T}+\sum \mathrm{w}_{1} \mathrm{x}_{1}\right)
$$

where $\mathrm{T}$ is a specific threshold value (bias) for each node and $f$ is a nonlinear sigmoid function. The performance of the formed networks was measured by a mean squared error (RMSE) and a coefficient of determination $\left(\mathrm{R}^{2}\right)$ on another set of data (set of tests). 
This dataset was not detected by the network during training and cross-validation $(\mathrm{CV})$, between predicted network values and target (or experimental) values. RMSE and $\mathrm{R}^{2}$ can be written as follows (Zangeneh et al., 2010):

$$
\begin{aligned}
R M S E & =\sqrt{\frac{1}{\mathrm{n}} \sum_{1}^{\mathrm{n}}\left(\mathrm{t}_{1}-\mathrm{z}_{1}\right)^{2}} \\
R^{2} & =1-\left(\frac{\sum_{i=1}^{n}\left(\mathrm{t}_{1}-\mathrm{z}_{1}\right)^{2}}{\sum_{i=1}^{n} t_{i}^{2}}\right)
\end{aligned}
$$

where $\mathrm{n}$ is the number of points in the data set, and $\mathrm{t}$ and $\mathrm{z}$ are the actual predicted output and output sets, respectively. We resume the presented procedure using the following figure.

\section{Multiple linear regression method to predict vehicles emissions}

In this paper, we propose the implementation of the multiple linear regression method to predict vehicle emissions. A multiple linear regression analysis is carried out to predict the values of a dependent variable, $\mathrm{Y}$, given a set of $\mathrm{p}$ explanatory variables $\left(\mathrm{x}_{1}, \mathrm{x}_{2}, \ldots, \mathrm{x}_{\mathrm{p}}\right)$. In multiple linear regression, there are $\mathrm{p}$ explanatory variables, and the relationship between the dependent variable and the explanatory variables is represented by the following equation:

$\mathrm{Y}_{\mathrm{i}}=\beta_{0}+\beta_{1} \mathrm{X}_{\mathrm{i} 1}+\beta_{2} \mathrm{X}_{\mathrm{i} 2}+\ldots+\beta_{\mathrm{p}} \mathrm{X}_{\mathrm{ip}}+\varepsilon_{\mathrm{i}, \mathrm{i}}=1, \ldots, \mathrm{n}$

where $Y_{i}$ is response variable, $i^{\text {th }}$ observation, $X_{i p}$ is Predictor variables $(p=0,1,2 \ldots p-1) \beta_{0}$ is $Y$ intercept of the regression plane $\beta_{p}$ is parameters $(p=0,1,2 \ldots p$ $1)$, and $\varepsilon_{\mathrm{i}}$ is random error in $Y$ for observation $i$.

So, multiple linear regression can be thought of an extension of simple linear regression, where there are $p$ explanatory variables, or simple linear regression can be thought of as a special case of multiple linear regression, where $p=1$. In this framework, it allows to study the impacts of vehicle characteristics on the emission rate of atmospheric pollutants $\mathrm{CO}, \mathrm{HC}, \mathrm{NOx}$ in order to analyze then the type of correlation between the emissions and the selected independent variables.

\section{RESULTS AND DISCUSSION}

A driving cycle was created taking into account a round trip ten times in the studied segment for the two vehicles. The collected data will be used to determine the vehicle emissions resumed on $\mathrm{HC}, \mathrm{NOx}$ and $\mathrm{CO}$ pollutants. Finally, the ANN and multiple linear regression methods will be adopted to develop two different models in order to predict vehicle emissions and studying the effect of different parameters in air pollution.

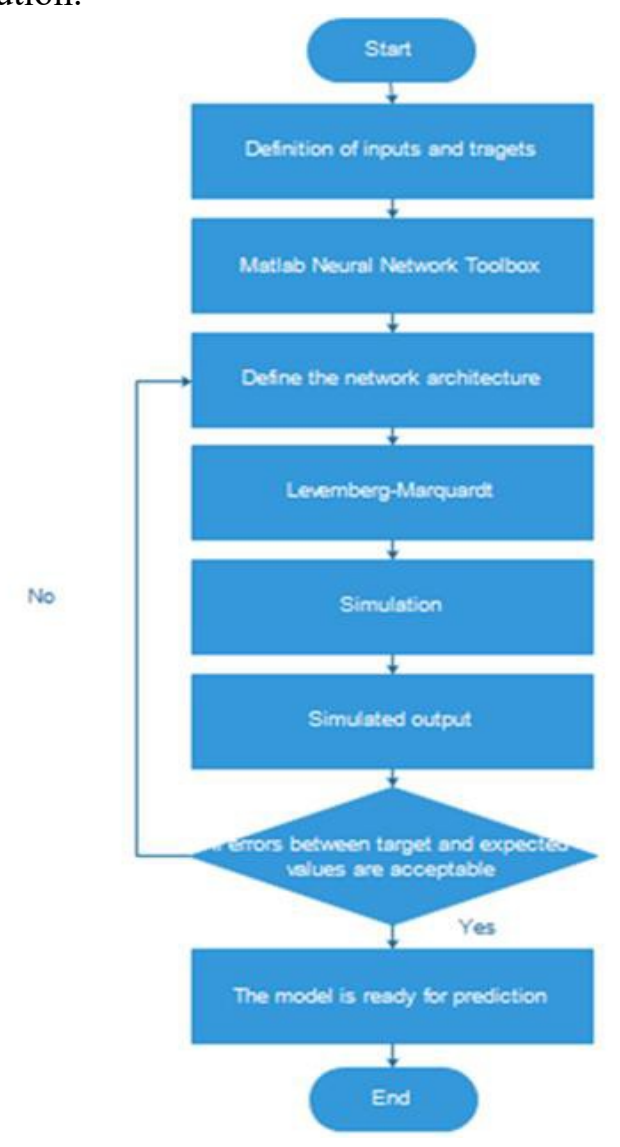

Fig. 4 ANN for vehicle emissions prediction

\section{Speed profiles}

In this section, we present the speed profiles for the two studied vehicles: LDV 3 and LDV 5. The speed limitation in the studied site is $90 \mathrm{~km} / \mathrm{h}$. Figure 5 indicates that the maximum speed reached by LDV 5 is around $81.3 \mathrm{~km} / \mathrm{h}$ but it is around $62.74 \mathrm{~km} / \mathrm{h}$ for the second one. Also, we detect deceleration and acceleration during the driving cycle because of the presence of speed kidney as a measure of security in the studied segment.
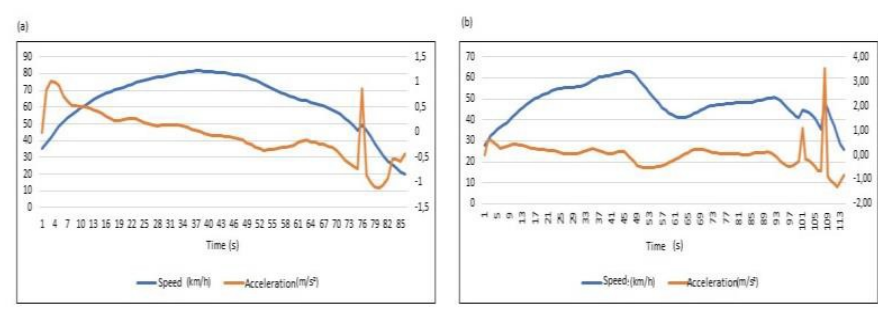

Fig. 5 Speed profile and acceleration (a) For LDV 5 (b) For LDV 3

\section{Quantification of emitted gas using Advisor}

In the following figures, the instantaneous emissions curves for both LDV5 and LDV3 vehicles are 
presented. Referring to Fig. 6, we record in the first 5 second the appearance of a peak in the emission of $\mathrm{HC}$ with an emission rate about $0.2 \mathrm{~g} / \mathrm{s}$.

The results indicate that the pollutant that took the highest share of the emission is the $\mathrm{CO}$ pursued by the $\mathrm{HC}$ and then by the NOx that tends to zero for both vehicles (Fig. 7). Also, the results indicate an increase in emissions of air pollutants, especially in the first seconds for both vehicles with very high values for LDV3. In addition, we notice the sensitivity of LDV5 to hydrocarbons all the way.

We summarize, using the Table 2, the average estimates of the emissions of the pollutants $\mathrm{HC}, \mathrm{CO}$ and NOx and of the fuel consumption of the two studied vehicles. According to these results, it is important to indicate that carbon monoxide is sensitive to the acceleration and hydrocarbons are also usually proportional to the fuel consumption rates and they can be higher in long deceleration events. In order to more illustrate emissions results, we present using Fig. 8 and Fig. 9 the emission rates of $\mathrm{CO}$ and $\mathrm{HC}$ and NOx for LDV5 and LDV 3. Referring to Fig. 8, we notice that emissions increase when the speed is greater than $50 \mathrm{~km} / \mathrm{h}$ and decrease when the average speed is $(20-50 \mathrm{~km} / \mathrm{h})$.

Among the factors that can contribute to the increase in $\mathrm{CO}$ level, the age of the vehicle in question, in fact, compared, LDV3 is the oldest. This can illustrate the faulty mechanical state of this car and subsequently its level of $\mathrm{CO}$ emission. In return, it is found that the emission of $\mathrm{HC}$ was greater in the LDV5 car than that LDV3. Similarly, driver behavior plays a fundamental role in emissions, in fact, more than the acceleration is high more than that leads to a larger emission. In other words, when the driving behavior is aggressive and not stable, where there is a sudden increase or decrease in speed, the emission rate will necessarily change. It is therefore necessary to have an eco-driving behavior, which is characterized by a stable and undisturbed speed. Moreover, the type of fuel also makes it possible to judge the emission level in the sense that when the engine is diesel type, it consumes a lesser amount of fuel than the gasoline, and therefore it emits fewer pollutants than the gasoline.

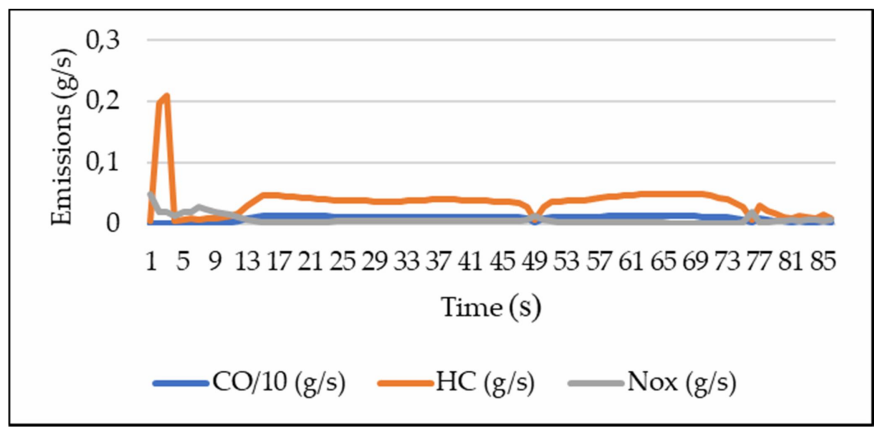

Fig. 6 Emissions of air pollutants for LDV5
Table 2. The average estimates of pollutants and fuel consumption

\begin{tabular}{ccc}
\hline Parameters & LDV 3 & LDV 5 \\
\hline Energy consumption $(1 / 100 \mathrm{~km})$ & 5.7 & 5.7 \\
CO $(\mathrm{g} / \mathrm{km})$ & 5.133 & 19.341 \\
$\mathrm{HC}(\mathrm{g} / \mathrm{km})$ & 2.081 & 3.012 \\
$\mathrm{NOx}(\mathrm{g} / \mathrm{km})$ & 0.343 & 0.914 \\
\hline
\end{tabular}

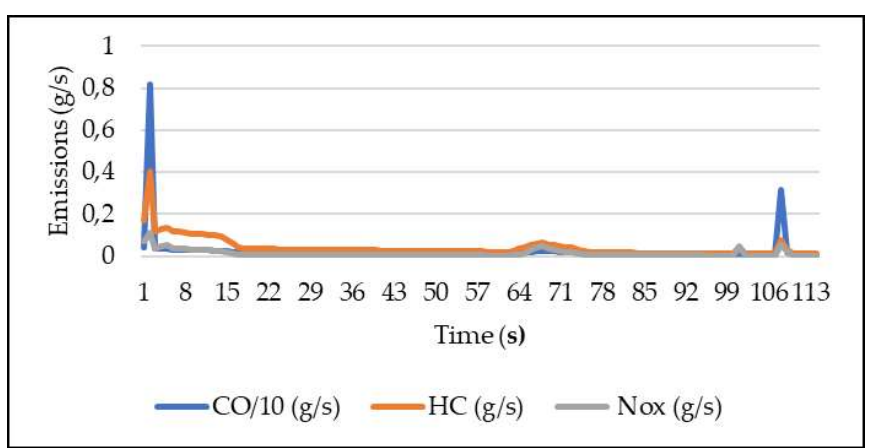

Fig. 7 Emissions of air pollutants for LDV3

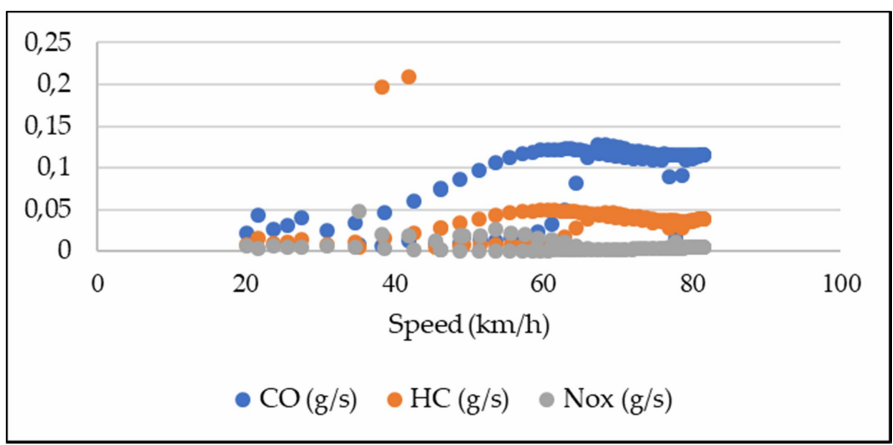

Fig. 8 Emissions rate of air pollutants for LDV5

\section{Modeling vehicle emission using ANN}

This section is consecrated to the implementation of ANN to develop mathematical models that allow to predict vehicle emissions. The MATLAB Neural Network Toolkit has been applied in this framework to perform neural network training analysis. We present, using Fig. 10, the regression curves of each pollutant for the two types of vehicles LDV3 and LDV5.

Figure 10 shows a good correlation between experimental data and predicted ones using artificial neural network. To more study the performance of this method, we resume in the Table 3, two several indicators which are: the coefficient of determination $\mathrm{R}^{2}$ and the mean square error RMSE. $\mathrm{R}^{2}$ denotes the coefficient of determination. The $\mathrm{R}^{2}$ allows to give the quality of the model fit. In fact, more than its value approaches 1 more than the model is considered good and estimable. On the other hand, more than the value of the RMSE is high, more than the model is not robust. According to indicators presented in Table 3, we can conclude the capability of the ANN method to estimate vehicle emissions with a good correlation between the average of 0.953-0.999 and a height precision on the quality of results. 

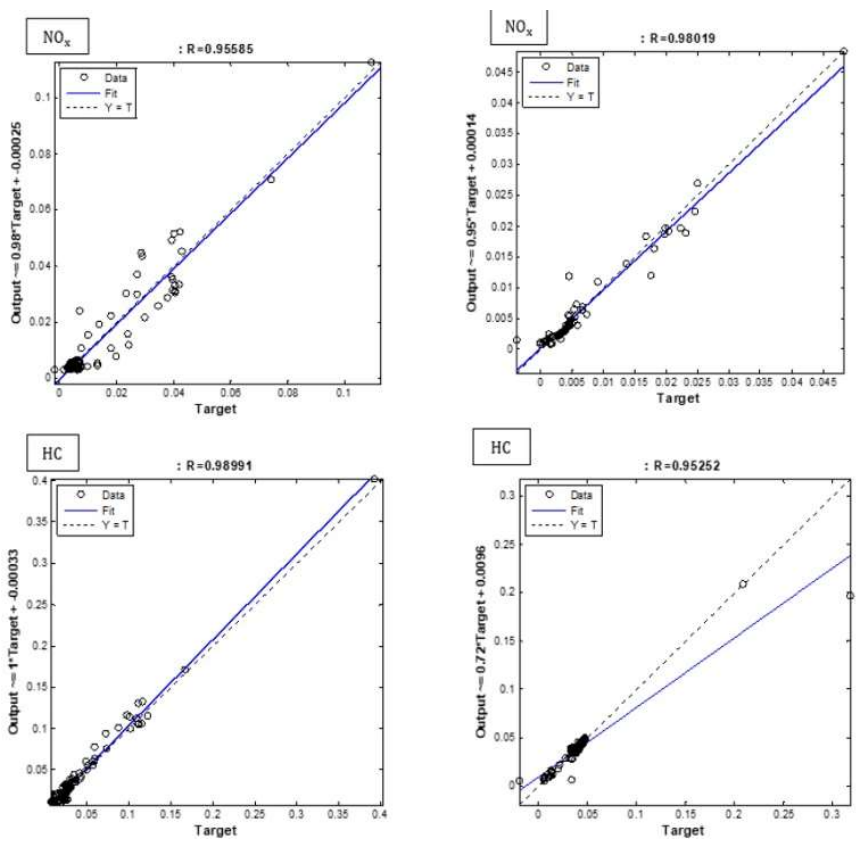

Fig. 10 The different curves of the regressions for each pollutant for the two types of vehicles LDV3 and LDV5

\section{Modeling vehicle emission using multiple linear regression}

We present, in this section, three emissions forecast models for two types of vehicles LDV3 and LDV5 in an urban segment using the multiple linear regression.CO, $\mathrm{HC}$ and $\mathrm{NOx}$ emissions were used as response variables. On the other hand, instantaneous speed, acceleration, altitude, and vehicle specific power (VSP) represent the predictor variables. The addition of this new variable (VSP) has been justified by several studies (Jiménez-Palacios, 1999; Younglove et al., 2002; Song, 2008; Song and Yu, 2009) that have proved that Vehicle Specific Power (VSP), as a parameter aimed at illustrating the instantaneous pulling power per unit mass of a car, can be applied as an explanatory variable in the emission prediction. In addition, the majority of recently developed vehicle pollutant emission models, such as MOVES and IVE have used the VSP to study the relationship between vehicle activities and emissions.

In utilities vehicles, the VSP model has been simplified by applying the typical values of the coefficient of aerodynamic drag, rolling resistance coefficients and the value of the air density at $20^{\circ} \mathrm{C}$. The model is thus defined by the following equation proposed by Jimenez- Palacios (1999):

VSP $=v[1.1 \mathrm{a}+9.81(\mathrm{a} * \tan (\sin ($ grade $)))+0.132]+0.00032 v^{3}$

where: $\mathrm{v}=$ vehicle speed $(\mathrm{m} / \mathrm{s})$, and $\mathrm{a}=$ acceleration of the vehicle $\left(\mathrm{m} / \mathrm{s}^{2}\right)$.

$$
\text { grade } \left.\left.(\text { degree })=\mathrm{h}_{\mathrm{t}=0}-\mathrm{h}_{\mathrm{t}=-1}\right) / v_{(\mathrm{t}=-1} \text { to } 0 \text { seconds }\right)
$$

Table 3. Results of Artificial neural network model

\begin{tabular}{cccc}
\hline \multirow{4}{*}{ Co } & CO & HC & NOx \\
\cline { 2 - 4 } & $\mathbf{R}^{\mathbf{2}}$ & $\mathbf{R}^{\mathbf{2}}$ & $\mathbf{R}^{\mathbf{2}}$ \\
& $\mathbf{R M S E}$ & $\mathbf{R M S E}$ & $\mathbf{R M S E}$ \\
\hline \multirow{2}{*}{ LDV 5 } & 0.962 & 0.953 & 0.980 \\
& 0.026 & 0.001 & 0.000 \\
\hline \multirow{2}{*}{ LDV 3 } & 0.999 & 0.991 & 0.956 \\
& 0.071 & 0.005 & 0.001 \\
\hline
\end{tabular}

MATLAB was used for stepwise data analysis to select statistically significant independent variables with emissions in a model. After performing model estimation, the significant variables in the correlation analysis will be selected for the final prediction model. The three models of multiple linear regressions considered are presented in equations (8), (9) and (10).

Model 1: The first multiple linear regression model is based on a polynomial combination of cubic terms of instantaneous velocity and acceleration are described as shown in the simplified equation:

$$
\mathrm{E}_{1}=\mathrm{a}_{1}+\mathrm{b}_{1} \times \mathrm{V}+\mathrm{c}_{2} \times \mathrm{Acc}+\mathrm{d}_{2} \times \text { Alt }
$$

Model 2: In this model, presented using Eq. 9, we tried to combine three parameters: speed, acceleration and altitude.

$$
\mathrm{E}_{2}=\mathrm{a}_{2}+\mathrm{b}_{2} \times \mathrm{V}+\mathrm{c}_{2} \times \text { Acc }+\mathrm{d}_{2} \times \mathrm{VSP}
$$

Model 3: To more exploit the vehicle emissions and factors that contribute to this phenomenon, we develop this third model which combines speed, acceleration and the vehicle speed power. After regression test, simulation results demonstrate the efficiency of this one to predict vehicle emissions based on the following expression:

$\mathrm{E}_{3}=\mathrm{a}_{3}+\mathrm{b}_{3} \times \mathrm{V}+\mathrm{c}_{3} \times \mathrm{Acc}+\mathrm{d}_{3} \times \mathrm{VSP}$

where: Acc $=$ acceleration $\left(\mathrm{m} / \mathrm{s}^{2}\right)$, Alt $=$ altitude $(\mathrm{m})$, VSP $=$ specific vehicle power $(\mathrm{Kw} / \mathrm{Ton})$. Then, we detail in the following expressions the proposed model to predict vehicle emissions using multiple linear regression method:

\footnotetext{
$E=$ constante $+V *\left(a 1+b 1 * V+c 1 * V^{2}+d 1 * A c c+e 1 * A_{c c}^{2}+f 1 * V S P\right.$ $\left.g 1 * \mathrm{Acc}^{2} * V S P\right)+A c c *\left(a 2+b 2 * A c c+c 2 * A c c^{2}+d 2 * V^{2}+e 2 * V S P+f 2 *(11)\right.$ $\left.V^{2} * V S P\right)+V S P *\left(a 3+b 3 * V^{2}+c 3 * V^{3}+d 3 * \mathrm{Acc}^{2}+83 * \mathrm{Acc}^{3}+f 3 * V * A c c\right.$
}

where:

$b_{c}=\left(a 1+b 1 * V+c 1 * V^{2}+d 1 * A c c+e 1 * A c c^{2}+f 1 * V S P+g 1 * A c c^{2} * V S P\right)(12)$

$c_{c}=\left(a 2+b 2 * A c c+c 2 * A c c^{2}+d 2 * V^{2}+e 2 * V S P+f 2 * V^{2} * V S P\right)(13)$

$d_{c}=\left(a 3+b 3 * V^{2}+c 3 * V^{3}+d 3 * A c c^{2}+e 3 * A c c^{3}+f 3 * V * A c c(14)\right.$

$a_{1}, b_{1}, \ldots, d_{1} ; a_{2}, b_{2}, \ldots, d_{2} ; a_{3}, b_{3}, \ldots, d_{3}$ the coefficients of equations.

$\mathrm{h}=$ altitude $(\mathrm{m})$ 
Table 4 presents the $\mathrm{R}^{2}$ and RMSE related to the developed model for each type of vehicles and for the three studied pollutants. The developed model, using multiple linear regression method, presents an acceptable correlation between data (0.732-0.921). We summarize results in the following Fig. 11. Based on the aforementioned results, we can conclude that both models produced reasonable coefficients of determination that determine the relationship between the predicted values and the recorded data. Nevertheless, it was found that some predicted values were negative for the regression models, a very undesirable condition, compared to the neural network model that it gave more accurate results and closer to the raw data. This demonstrates the superiority of the ANN method in prediction precisely the vehicles emissions.

\section{CONCLUSIONS}

The prediction of various air pollutants and emissions with an adverse external effect on climate plays an undeniable role, as these measures provide a scientific basis for the preparation of solutions and the application of regulatory policies and strategies and an option to cope with the massive escape of polluting gases in order to improve energy and environmental efficiency and to achieve the objectives of sustainable development. The main objective of this work is to develop a mathematical model to predict vehicular emissions under various traffic conditions and vehicle's parameters in an urban segment in the Sousse city. To deal with this objective, the artificial neural network and multiple linear regression have been used as a tool allowing the development of empirical models allowing the prediction of vehicle emissions.

The studied area was an urban segment in the region of Sousse in Tunisia. We tried, firstly, to determine speed profiles and acceleration for two different vehicles. Then, the collected data have been used to calculate the pollutants based on the Advisor simulation tool in order to determine $\mathrm{HC}, \mathrm{NOx}$ and $\mathrm{CO}$ emitted during the studied cycle. In conclusion, speed and acceleration are the most influential parameters in increasing emissions. The vehicle emissions are minimal when the average speed is between 20 and 50 $\mathrm{km} / \mathrm{h}$. The driving style and characteristics of the

Table 4. Results of multiple linear regression model

\begin{tabular}{cccc}
\hline & $\mathbf{C O}$ & $\mathbf{H C}$ & NOx \\
\cline { 2 - 4 } & $\mathbf{R}^{\mathbf{2}}$ & $\mathbf{R}^{\mathbf{2}}$ & $\mathbf{R}^{\mathbf{2}}$ \\
& $\mathbf{R M S E}$ & $\mathbf{R M S E}$ & $\mathbf{R M S E}$ \\
\hline \multirow{2}{*}{ LDV 5 } & 0.897 & 0.951 & 0.921 \\
& 0.015 & 0.007 & 0.002 \\
\multirow{2}{*}{ LDV 3 } & 0.723 & 0.836 & 0.847 \\
& 0.468 & 0.021 & 0.007 \\
\hline
\end{tabular}
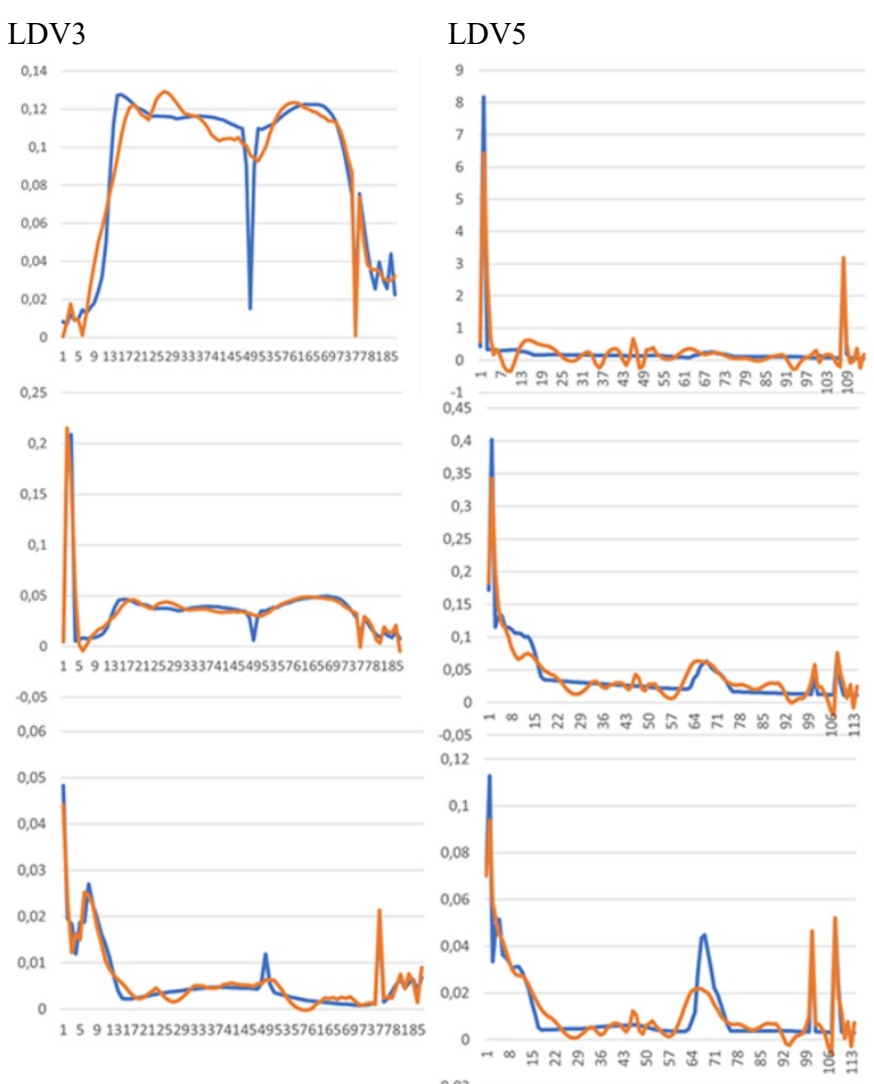

Fig. 11 Correlation between predicted data and advisor data for each pollutant for the two types of vehicles LDV3 and LDV5

vehicle have a significant impact on the emission rates. That fore we must search for an eco-driving and a modeling of the conductor behavior. Also, the specific power of vehicles has a large influence on emissions. The use of multiple linear regression and the artificial neural network allowed to model and predict vehicle emissions with an acceptable correlation. The coefficient of determination $\mathrm{R}^{2}$ was between 0.723 and 0.921 for the multiple linear regression model and between 0.953 and 0.999 in the case of the ANN model. These results demonstrate the capability and efficiency of the ANN to predict successfully vehicles emissions and guarantees a good correlation between data.

The developed models can be used to optimize and minimize vehicle emissions by determining the optimal parameters and optimal traffic conditions that allow minimization of emitted pollutants.

\section{REFERENCES}

Ahn K, Rakha H. Field Evaluation of Energy and Environmental Impacts of Driver Route Choice Decisions. 2007; 24061:730-5. Ahn K, Rakha H. System-Wide Impacts of Green Extension Transit Signal Priority. 2006;91-6

Ahn K., Trani A.A., Rakha H.A., Van Aerde M. (1999). Microscopic Fuel Consumption and Emission Models. Presented at the Transportation Research Board 78th Annual Meeting, January.

Ahn. K; Rakha.H; Antonio Trani, and Michel Van Aerde; Microframework for modeling of high-emitting vehicles; Journal 
of the transportation research bord; January 2004, Volume: 1880 issue: 1, page(s): $39-49$.

Barth, M. and Boriboonsomsin, K. (2008) Real-World Carbon Dioxide Impacts of Traffic Congestion. Transportation Research Record, 163-171.

Barth M., Younglove T., Wenzel T., Scora G., An F., Ross M., and Norbeck J. (1997), Analysis of Model Emissions from Diverse InUse Vehicle Fleet, Transportation Re-search Record 1587, pp. 7384.

Bassel Othman, Giovanni De Nunzio, Domenico Di Domenico, Carlos Canudas-de-Wit2; Variable Speed Limits Control in an Urban Road Network to Reduce Environmental Impact of Traffic. Conference: IEEE American Control Conference (ACC) 2020.

Behera, S.N.; Sharma, M.; Mishra, P.K.; Nayak, P.; Damez-

Fontaine, B.; Tahon, R. Passive measurement of NO2 and application of GIS to generate spatially-distributed air monitoring network in urban environment. Urban Clim. 2015, 14, 396-413.

Othman, B., De Nunzio, G., Di Domenico, D., Canudas-de Wit, C. (2019). Ecological traffic management: A review of the modeling and control strategies for improving environmental sustainability of road transportation. Annual Reviews in Control, 2019.

Davis, G.K., D'Alessio, J.A., Patel, N.H. (2005). Pax3/7 genes reveal conservation and di-vergence in the arthropod segmentation hierarchy. Dev. Biol. 285(1): 169--184.

Di Mascio, P.; Di Vito, M.; Loprencipe, G.; Ragnoli, A. Procedure to determine the geometry of road alignment using GPS data. Procedia-Soc. Behav. Sci. 2012, 53, 1202-1215

Directive 2002/49/ec of the European parliament and of the council of 25 June 2002 relating to the assessment and management of environmental noise.

Elena Agirre Basurko, G. Ibarra-Berastegi and I. Madariaga, Regression and multilayer perceptron-based models to forecast hourly $\mathrm{O} 3$ and NO2 levels in the Bilbao area. Environmental Modelling and Software 21(4):430-446.

Feng, Xiao, et al. "The Application of the IVE Model for Establishing the Vehicle Emission Inventory in the Urban Areas of Chongqing." Applied Mechanics and Materials, vol. 361-363, Trans Tech Publications, Ltd., Aug. 2013, pp. 854-859. Cross ref, doi: 10.4028/www.scientific.net/amm.361-363.854.

Gardner, M.W. and Dorling, S.R. (1998) Artificial Neural Networks (the Multilayer Perceptron)-A Review of Applications in the Atmospheric Sciences. Atmospheric Environment, 32,2627-2636. Hausberger, S. (2003). Simulation of Real-World Vehicle Exhaust Emissions. Graz University of Technology. VKM-THD Mitteilungen Heft/Volume 82. ISBN 3-901351-74-

Hausberger, S., Matzer, C. (2017). Update of Emission Factors for

EURO 4, EURO 5 and EURO 6 Diesel Passenger Cars for the HBEFA Version 3.3, Final report No. Report No. I-09/17/ CM EM 16/26/679 from 01.06.2017

Hassine H, Barkallah M, Bellacicco A, Louati J, Riviere A, Haddar, M. (2015). Multi objective optimization for sustainable manufacturing, application in turning. International Journal of Simulation Modelling 14(1):98-109

Hamad, K.; Khalil, M.A.; Shanableh, A. Modeling roadway traffic noise in a hot climate using artificial neural networks. Transp. Res. Part D. Transp. Environ. 2017, 53, 161-177

ISSRC. (2008). International Sustainable Systems Research Center, IVE Model User Manu-al, Version 2.0.

Jiménez-Palacios, J. Understanding and Quantifying Motor Vehicle Emissions with Vehicle Specific Power and TILDAS Remote Sensing. PhD dissertation. Massachusetts Institute of Technology, Cambridge, Mass., 1999.

Johnson, M.; Isakov, V.; Touma, J.S.; Mukerjee, S.; Özkaynak, H. Evaluation of land-use regression models used to predict air quality concentrations in an urban area. Atmos. Environ. 2010, $44,3660-3668$
Koupal, J. et al., 2010. Design and Implementation of MOVES: EPA's New Generation Mobile Source Emission Model, Ann Arbor, MI: U.S. EPA Office of Transportation and Air Quality.

Kanaroglou, P.S.; Adams, M.D.; De Luca, P.F.; Corr, D.; Sohel, N. Estimation of sulfur dioxide air pollution concentrations with a spatial autoregressive model. Atmos. Environ. 2013, 79, 421-427.

Wipke, K., Cuddy, M., Bharathan, D., Burch, S., Johnson, V., Markel A., Sprik, S. (1999). Advisor 2.0: A Second-Generation Advanced Vehicle Simulator for Systems Analysis, March 1999, NREL/TP-540-25928.

Maazen Alsabaan, Kshirasagar Naik, Tarek Khalifa and Amiya Nayak; Applying vehicular Networks for Reduced Vehicle Fuel Consumption and $\mathrm{CO} 2$ Emissions; Intelligent Transportation Systems, March 2014

Negrenti. E (1998). Consumption and emission models: results from action COST 319. ENEA report, ${ }^{\circ}$ RTI-ERG-SIRE-98/19, Rome, 1998, p.39.

Nikolaos. T, Joakim.E, Johan.O; Estimating Emissions from Static Traffic Models: Problems and Solutions; February 2020Journal of advanced transportation 2020(3):1-17: DOI: $10.1155 / 2020 / 5401792$

Ntziachristos, L., Samaras, Z., 2000. Speed-dependent representative emission factors for catalyst passenger cars and influencing parameters. Atmospheric Environment 34, 4611-4619.

Omer Saud Azeez; Biswajeet Pradhan; Helmi Z. M. Shafri; Nagesh Shukla; Chang-Wook Lee; and Hossein Mojaddadi Rizeei, Modeling of CO Emissions from Traffic Vehicles Using Artificial Neural Networks; Appl. Sci. 2019, 9, 313; doi:10.3390/app9020313.

P. Fajri, S. Lee, V. A. K. Prabhala and M. Ferdowsi; Modeling and Integration of Electric Vehicle Regenerative and Friction Braking for Motor/Dynamometer Test Bench Emulation; IEEE Transactions on Vehicular Technology; 2015

Quan Dai, Hongfei Jia, Yao Liu; Private vehicle-based crowd shipping for intercity express transportation: Feasibility assessment; February 2020International Journal of Distributed Sensor Networks 16(2). DOI: 10.1177/1550147720908203

Rakha HA, Trani AA. MESOSCOPIC FUEL CONSUMPTION AND EMISSION MODELING By In partial fulfillment of the requirements for the degree of. 2008.

Rakha, Van Aerde, Ahn, Trani. Requirements for evaluating traffic signal control impacts on energy and emissions based on instantaneous speed and acceleration measurements. Transportation Research Board 79th Annual Meeting January 9-

13, 2000 Washington, D.C.

Singh, D.; Kumar, A.; Kumar, K.; Singh, B.; Mina, U.; Singh, B.B.; Jain, V.K. Statistical modeling of O3, NOx, CO, PM2. 5, VOCs and noise levels in commercial complex and associated health risk assessment in an academic institution. Sci. Total Environ. 2016, 572, 586-594

Specht, D.F., 1991. A general regression neural network. IEEE Trans. Neural Networks, 2: 568-576. DOI: 10.1109/72.97934.

Song, G. Development of Fuel Consumption and Vehicle Emission Models for Evaluation of Transportation Strategies. PhD dissertation. Beijing Jiaotong University, Beijing, 2008.

Song, G., and L. Yu. Estimation of Fuel Efficiency of Road Traffic by Characterization of Vehicle-Specific Power and Speed Based on Floating Car Data. In Transportation Research Record: Journal of the Transportation Research Board, No. 2139, Transportation Research Board of the National Academies, Washington, D.C., 2009, pp. 11-20.

Younglove, T. et al., (2002) "Mobile Source Emissions New Generation Model: Using a Hybrid Database Prediction Technique", final report submitted to U.S. EPA, see http://www.epa.gov/otaq/models/ngm/cecert.pdf, Accessed July 2004. 
Tomi'c, J.; Bogojevic, N.; Pljakic, M.; Šumarac-Pavlovic, D. Assessment of traffic noise levels in urban areas using different soft computing techniques. J. Acoust. Soc. Am. 2016, 140, EL340-EL345.

UK NAEI, 2016. United Kingdom National Atmospheric Emissions Inventory

Unal, A., Frey, H.C., Rouphail, N.M., 2004. Quantification of highway vehicle emissions hot spots based upon on-board measurements.
Vandaele, N.; Van Woensel, T.; Verbruggen, A. A queueing-based traffic flow model. Transp. Res. Part D Transp. Environ. 2000, 5, 121-135.

Zangeneh M., Omid M., Akram A., 2010. A comparative study on energy use and cost analysis of potato production under different farming technologies in Hamadan province of Iran. Energy 35, 2927-2933.

Zhao Z, Chow TL, Rees HW, Yang Q, Xing Z, Meng F-R. Predict soil texture distributions using an artificial neural network model. Computers and Electronics in Agriculture. 2009; 65:36-48. 